\title{
Avaliação do potencial uso do colutório à base de própolis para utilização no pré e pós cirúrgico
}

\author{
Evaluation of the potential of using a propolis-based mouthwash for use in the pre- and \\ pos operative period
}
Evaluación del potencial del uso de enjuague bucal a base de propóleo para su uso em el período pre y postoperatorio

Iara Dalva dos Santos ${ }^{1 *}$, Andreza Silva Oliveira ${ }^{1}$, Ana Flávia Ribeiro Tadim ${ }^{1}$, Priscila Faquini Macedo ${ }^{1}$, Rachel Rocha Pinheiro Machado'.

\section{RESUMO}

Objetivo: Avaliar o potencial antisséptico de colutório à base de própolis. Métodos: Foi realizado estudo longitudinal prospectivo, sendo selecionados 40 voluntários, divididos em quatro grupos de acordo com o tempo e 0 enxaguatório a serem testados, tendo como controle 0 enxaguatório à base de clorexidina $(\mathrm{C} 1=$ Clorexidina por 1 minuto); $(\mathrm{C} 30$ = clorexidina por 30 segundos $) ;(\mathrm{P} 1=$ própolis por 1 minuto; $\mathrm{P} 30$ = própolis por 30 segundos). $O$ grau de turbidez da solução salina estéril e o crescimento bacteriano foram verificados em placas de Petri. A percepção dos voluntários sobre o sabor dos enxaguatórios bucais foi verificada com a aplicação de um questionário. Ao final, os dados foram avaliados estatisticamente. Resultados: Houve diferença no nível de turbidez e crescimento bacteriano entre os dois enxágues, utilizando clorexidina por 1 minuto com menor grau de turbidez e maior cobertura antibacteriana, sem diferença significativa na percepção do paladar. Conclusão: Concluiu-se que, na comparação dos enxaguatórios bucais, a clorexidina inibe o crescimento bacteriano de forma mais eficaz nos dois períodos analisados, não sendo, portanto, o enxaguatório à base de própolis uma boa alternativa, apesar de também ter mostrado atividade antibacteriana.

Palavras-chaves: Clorexidina, Própolis, Procedimentos cirúrgicos bucais.

\begin{abstract}
Objective: Evaluate the antiseptic potential of propolis-based mouthwashes. Methods: It was performed a prospective longitudinal study with 40 volunteers were selected, divided into four groups according to the time and mouthwash to be tested, with the chlorhexidine-based mouthwash as control $(\mathrm{C} 1=$ Chlorhexidine for 1 minute); $(\mathrm{C} 30=$ chlorhexidine for 30 seconds $)$; $(\mathrm{P} 1=$ propolis for 1 minute; $\mathrm{P} 30=$ propolis for 30 seconds $)$. The degree of turbidity of the sterile saline solution and the bacterial growth were verified in Petri dishes. The volunteers' perception of the taste of mouthwashes was verified with the application of a questionnaire. At the end, the data were evaluated statistically. Results: There was a difference in the level of turbidity and bacterial growth between the two rinses, using chlorhexidine for 1 minute with a lower degree of turbidity and greater antibacterial coverage, with no significant difference in the perception of taste. Conclusion: It was concluded that, when comparing mouthwashes, chlorhexidine inhibits bacterial growth more effectively in the two analyzed periods, therefore, the propolis-based mouthwash is not a good alternative, although it has also shown antibacterial activity.
\end{abstract}

Keywords: Chlorhexidine, Propolis, Oral surgical procedures.

${ }^{1}$ Faculdade das Ciências Médicas e da Saúde de Juiz de Fora (FCMS/JF), Juiz de Fora - MG.

*E-mail: iaradalva@hotmail.com 


\section{RESUMEN}

Objetivo: Evaluar el potencial antiséptico de enjuagues bucales a base de propóleo Métodos: Se realizó un estudio longitudinal prospectivo y se seleccionaron 40 voluntarios, divididos en cuatro grupos según el tiempo y el colutorio a ensayar, con el colutorio a base de clorhexidina como control $(\mathrm{C} 1=\mathrm{Clorhexidina} \mathrm{por}$ 1 minuto); (C30 = clorhexidina durante 30 segundos); $(\mathrm{P} 1=$ propóleo durante 1 minuto; $\mathrm{P} 30$ = propóleo durante 30 segundos). El grado de turbidez de la solución salina estéril y el crecimiento bacteriano se verificaron en placas de Petri. La percepción de los voluntarios del sabor de los enjuagues bucales se verificó con la aplicación de un cuestionario. Al final, los datos se evaluaron estadísticamente. Resultados: Hubo diferencia en el grado de turbidez y crecimiento bacteriano entre los dos enjuagues, utilizando clorhexidina durante 1 minuto con menor grado de turbidez y mayor cobertura antibacteriana, sin diferencia significativa en la percepción del gusto. Conclusión: Se concluyó que, al comparar enjuagues bucales, la clorhexidina inhibe el crecimiento bacteriano de manera más efectiva en los dos periodos analizados, por lo que el enjuague bucal a base de propóleo no es una buena alternativa, aunque también ha mostrado actividad antibacteriana.

Palabras clave: Clorhexidina, Procedimientos, Quirúrgicos orales.

\section{INTRODUÇÃO}

A realização de procedimentos cirúrgicos odontológicos requer como um de seus cuidados pré e pós operatório, garantir a menor população microbiana possível na cavidade bucal para se reduzir ao máximo o estabelecimento de infecções nos sítios cirúrgicos, bem como a evolução para quadros de infecções sistêmicas de origem bucal, pois a cavidade bucal abriga uma complexa microbiota, apresentando cerca de 700 ou mais espécies bacterianas diferentes, sendo a maioria delas comensais e essenciais para a manutenção da saúde bucal (CHEN WP, et al., 2018).

No entanto, alguns microrganismos têm a capacidade de acessar a circulação sanguínea invadindo a mucosa, que em procedimentos odontológicos invasivos, se torna mais susceptível, contribuindo para o desencadeamento de bacteremias nestes procedimentos, principalmente durante as extrações dentárias, tendo em vista que a incidência de bacteremia nestes procedimentos é de 70-80\% (MANAGUTTI A, et al., 2017).

Devido a este fato, os enxaguatórios bucais utilizados pelo paciente têm por objetivo a redução da população microbiana da cavidade bucal, diminuindo o risco de infecções sistêmicas (ARAÚJO DB, et al., 2015).

A clorexidina $(\mathrm{CHX})$, considerada padrão ouro entre os enxaguatórios bucais, é o agente químico mais empregado no controle de bacteremia após cirurgias odontológicas (SANTOS GO, et al., 2017; BARATAKKE SU, et al., 2017; ARTEAGOITIA A, et al., 2018).

Ela apresenta efeito antimicrobiano com ação bactericida para as bactérias Gram positivas, como Staphylococcus aureus, Enterococcus faecalis e Streptococcus sp, porque é capaz de interagir com a membrana plasmática do microrganismos de forma mais severa, fazendo com que a membrana adquira um estado líquido cristalino e altere sua estrutura, causando escape de material celular, levando à morte celular. Porém, quando utilizada em menores concentrações apresenta ação bacteriostática, pois não é suficiente para causar morte celular, apenas inibe seu crescimento (DENNY J e MUNRO CL, 2017; BARATAKKE SU, et al., 2017).

Essas concentrações se apresentam em $0,12 \%, 0,2 \%$ e $2 \%$, sendo a primeira a mais recomendada devido à relação da efetividade antimicrobiana com os possíveis efeitos colaterais (BARATAKKE SU, et al., 2017; DENNY J E MUNRO CL, 2017).

Neste sentido, a CHX é indicada por curtos períodos de tempo, uma vez que causa manchas de coloração castanha nos dentes e língua, alteração do paladar, sensação de queimação e pigmentação dos tecidos moles da boca, descamação e sensibilidade da mucosa bucal (BARATAKKE SU, et al., 2017). 
Apesar das vastas evidências clínicas e científicas sobre a eficácia do uso da $\mathrm{CHX}$ como enxaguante bucal, alternativas devem ser buscadas a fim de ampliar o leque de possibilidades de colutórios a serem aplicados na prática clínica odontológica, pois este colutório apresenta, como já citado, efeitos adversos às vezes não tolerados pelos pacientes, fato que pode levar a complicações de todo o procedimento, uma vez que o paciente estará mais exposto a processos infecciosos. Neste sentido, a fitoterapia serve como principal fonte de terapia complementar e, a própolis apresenta propriedades antimicrobianas e antiinflamatórias já comprovadas e há muito tempo é utilizada pela população por estas características, como descrito em revisão realizada por (BOHNEBERGER G, et al., 2019).

A própolis, conhecida como "cola de abelha", é uma substância resinosa natural, semelhante à cera (VAGISH KLS, 2014; KHURSHID Z, et al., 2017; AIREN B, et al., 2018) produzida através da secreção das glândulas hipofaringeanas como resultado da digestão de resinas provenientes de folhas, flores de plantas e árvores, empregadas como selante e esterilizador em colméias (VAGISH KLS, 2014) e sua composição química varia de acordo com a área geográfica na qual é coletada, na condição ambiental do local de coleta, na origem e tipo de pólen vegetal e na espécie de abelha que a produziu (AIREN B, et al., 2018).

Esse composto orgânico tem como principais representantes os flavonóides e o ácido caféico, que atuam na membrana citoplasmática ou na parede celular microbiana, causando danos funcionais e estruturais (AKCA AE, et al., 2016).

Além disso, atuam reduzindo a resposta inflamatória através da inibição das enzimas lipoxigenase e cicloxigenase, que impedem que o ácido araquidônico converta em prostaglandinas e leucotrienos, diminuindo as possibilidades de inflamação e dor (BOHNEBERGER G, et al., 2019).

Neste sentido, é possível verificar que a própolis é um composto com propriedades antibacterianas, antiinflamatórias, imunomoduladoras, antiulcerativa, antitumoral e de baixa toxicidade (TORETI VC, et al., 2013; MORAWIEC T, et al., 2015). Entretanto, apesar dos aspectos positivos da própolis e, assim como a CHX, ela apresenta limitações em relação ao seu uso, pois deve ser evitado por pessoas alérgicas ao pólen, picadas de abelha e crianças menores de 2 anos (BOHNEBERGER G, et al., 2019).

Considerando as propriedades da própolis e o conhecimento de suas limitações de uso, investigar seu potencial uso como colutório a ser utilizado nos procedimentos pré e pós cirúrgicos contribui para as investigações por alternativas às soluções à base de clorexidina. Neste sentido, o presente estudo compara a ação antisséptica do colutório à base de própolis ao padrão ouro considerando dois diferentes tempos de bochecho pelos voluntários.

\section{MÉTODOS}

\section{Delineamento do Estudo}

Foi realizado um Estudo Longitudinal Prospectivo no qual 40 participantes foram distribuídos em quatro grupos. Para cada participante era entregue às cegas um copinho plástico contendo colutório à base de $\mathrm{CHX}$ ou à base de própolis para realizarem bochecho por 30 segundos ou 60 segundos. Após o bochecho era então realizada a coleta da amostra de microbiota por passagem de swab na região jugal próxima aos molares inferiores, bem como assoalho da cavidade bucal. Estes swabs eram imediatamente acondicionados em tubos contendo solução salina estéril $(5 \mathrm{~mL})$ e os voluntários respondiam ao questionário contendo as seguintes perguntas: De acordo com enxaguante bucal, classifique o qual o grau do sabor? Qual o grau de ardência na boca? qual o grau de ardência após o uso do enxaguante bucal? Qual o grau de ardência na ferida? Classifique de acordo com o odor(cheiro). Classifique com alteração de paladar durante o uso do enxaguante. Em cada pergunta, o participante poderia classificar como 0 a 3 (ruim) de 4 a 7 (moderado), de 8 a 10(ótimo) ou não sei opinar.

O único dado do questionário utilizado para análise estatística foi sobre a percepção do sabor, pois não gerou nenhuma dúvida durante a realização do mesmo. As demais questões não foram utilizadas para análise dos dados porque gerou dúvidas nos avaliados. Portanto, esse fato gera um viés, invalidando a pesquisa baseada nesta ferramenta. Diante disso, é importante que novos estudos sejam realizados para que aprimorem o questionário. 
Dessa forma, os grupos deste estudo foram os seguintes: C30 ( $n=10-30$ segundos de bochecho com clorexidina); C1 ( $n=10$ - 1 minuto de bochecho com clorexidina); P30 ( $n=10$ - 30 segundos de bochecho com solução de própolis); P1 ( $n=10$ - 1 minuto de bochecho com solução de própolis). O estudo foi autorizado pelo Comitê de Ética em Pesquisa sob o número 3.548 .338 e todos os voluntários assinaram o Termo de Consentimento Livre e Esclarecido.

\section{Preparo dos colutórios bucais}

O colutório à base de clorexidina foi preparado com digluconato de clorexidina a $0,12 \%$ e o colutório à base de própolis foi preparado pela farmacêutica Silvia Garcia Sales, CRF 111,com extrato glicol de própolis a 20\%, glicerina 10\% e água, na farmácia de manipulação Santos em Juiz de Fora- MG.

\section{Semeadura e cultura da amostra.}

O swab do tubo de solução salina foi transferido para um tubo contendo 5,0mL de meio Brain Heart Infusion (BHI). Em seguida, 100 $\mu \mathrm{L}$ deste meio contendo o swab fora inoculado em Placas de Petri contendo Ágar Muller Hinton ou Ágar Sangue. A amostra foi semeada com auxílio de alça Drigalski e as Placas de Petri foram acondicionadas em estufa de cultura à $36,5^{\circ} \mathrm{C}$ por um período de $12-18$ horas, bem como as suspensões bacterianas em solução salina e em meio BHI (OPLUSTIL CP, et al., 2010).

Os tubos contendo as soluções salinas que haviam recebido inicialmente os swabs foram utilizados para se verificar o crescimento através da visualização da turbidez por comparação com a escala nefelométrica de Mc Farland. Esta é uma escala de turbidez constituída por 11 tubos, enumerados de 0,5 a 10, cujo padrão de turvação é o mais frequentemente utilizado nos laboratórios de microbiologia do Brasil e dos Estados Unidos, para determinar a intensidade de multiplicação bacteriana em meios líquidos. A multiplicação bacteriana se opõe à passagem da luz, o que provoca a turvação e a opacificação do meio. Quanto maior o número de bactérias presentes na amostra, maior será o grau de turvação do meio de cultura e maior será o número do tubo referente ao padrão de turbidez visualizado. O uso da escala é recomendado pela Clinical and Laboratory Standards Institute (CLSI) nos Estados Unidos, tendo sido adotada e também recomendada pela ANVISA no Brasil (NCCLS, 2011).

O uso da solução salina neste caso é relevante pois se trata de um meio translúcido de coloração idêntica ao da escala de número 0,5 da escala Mc Farland. Os tubos contendo meio BHI e o swab com as amostras da microbiota dos participantes serviram como controle para certificar o crescimento dos microrganismos na solução salina.

\section{Análise dos Resultados}

Após o período de incubação foi realizada a leitura das culturas (contagem) conforme o número de Unidades Formadoras de Colônias (UFC), sendo definido um sistema de cruzes para o padrão de crescimento: 0 cruz = nenhuma UFC; 1 cruz = muito pouco crescimento ( $\leq 10$ UFC); 2 cruzes = moderado $(>10 \leq 50$ UFC); 3 cruzes = elevado (>50 UFC). As placas foram analisadas individualmente por 4 avaliadoras, sendo que, os resultados diferentes foram reavaliados em conjunto. A avaliação da turbidez da solução salina também foi realizada individualmente por quatro avaliadoras e da mesma forma, os resultados diferentes foram reavaliados em conjunto.

Os dados obtidos foram então submetidos à análise estatística. Inicialmente foram realizadas análises exploratórias e descritivas dos dados. Para análise da contagem de UFC (crescimento bacteriano), foram consideradas as medianas dos escores $(0,1,2,3$ ou 4) de cada participante. Como os dados não atendem às pressuposições de uma análise paramétrica, foram então analisados por testes não paramétricos.

Para a comparação considerando os tempos e os tipos de enxaguatórios quanto aos valores de turbidez e os escores de placas (crescimento bacteriano) foi utilizado o teste de Mann Whitney. Para as análises de associação dos grupos com a classificação de turbidez e escore de sabor foi utilizado o teste Exato de Fisher. Todas as análises foram realizadas no programa $\mathrm{R}$ com nível de significância de $5 \%$. $\mathrm{R}$ Core Team (2019). R (A language and environment for statistical computing. R Foundation for Statistical Computing, Vienna, Austria). 


\section{RESULTADOS}

Os resultados das investigações a fim de comparar a ação antimicrobiana e a sensibilidade dos participantes aos colutórios à base de própolis e clorexidina serão descritos a seguir. Em relação à avaliação do potencial inibitório do crescimento microbiano entre os diferentes colutórios, realizado através da comparação do crescimento microbiano utilizando a escala nefelométrica, foi possível verificar um desenvolvimento microbiano significativamente menor $(p<0,05)$ nos tubos derivados da coleta pós-bochecho com clorexidina e também, uma ausência de diferença significativa entre os tempos aplicados para ambos os colutórios, ou seja, a proteção oferecida pelos tempos de bochecho 30 segundos e um minuto, não apresentaram diferença estatística (Tabela 1).

Tabela 1 - Mediana (valor mínimo e máximo) dos valores de turbidez da solução salina após aproximadamente 12 horas de cultura, em função do enxaguatório e tempo de bochecho.

\begin{tabular}{cccc}
\hline Enxaguatórios & \multicolumn{2}{c}{ Tempo de bochecho } & p-valor \\
\hline & $\mathbf{3 0}$ segundos & Um minuto & \\
À base de própolis & $2,25(1,50-3,00) \mathrm{a}$ & $2,25(1,00-2,50) \mathrm{a}$ & 0,3847 \\
À base de clorexidina & $0,75(0,30-2,50) \mathrm{b}$ & $0,50(0,30-2,00) \mathrm{b}$ & 0,2207 \\
p-valor & 0,0025 & 0,0019 & \\
\hline
\end{tabular}

Legenda: Letras diferentes comparando na vertical indicam diferença significativa $(p \leq 0,05)$.

Fonte: Santos ID, et al., 2020.

Entretanto, ao analisarmos esses dados em relação ao comportamento do crescimento microbiano através do Boxplot (Gráfico 1), é possível observar que os valores obtidos com 1 minuto de exposição à clorexidina, foram menores e menos variados, demonstrando que o tempo de 1 minuto, oferece maior segurança ao paciente. Em relação ao colutório à base de própolis, uma observação semelhante pode ser notada, porém, ao compararmos os colutórios entre si, é evidenciada uma tendência do colutório à base de própolis apresentar menor capacidade de inibir o crescimento microbiano nos dois tempos, sugerindo que nos tempos testados, ele ainda não se configure como uma boa alternativa.

Gráfico 1 - Boxplot dos valores de turbidez da solução salina, após aproximadamente 12 horas de cultura, em função do enxaguatório e tempo de bochecho.

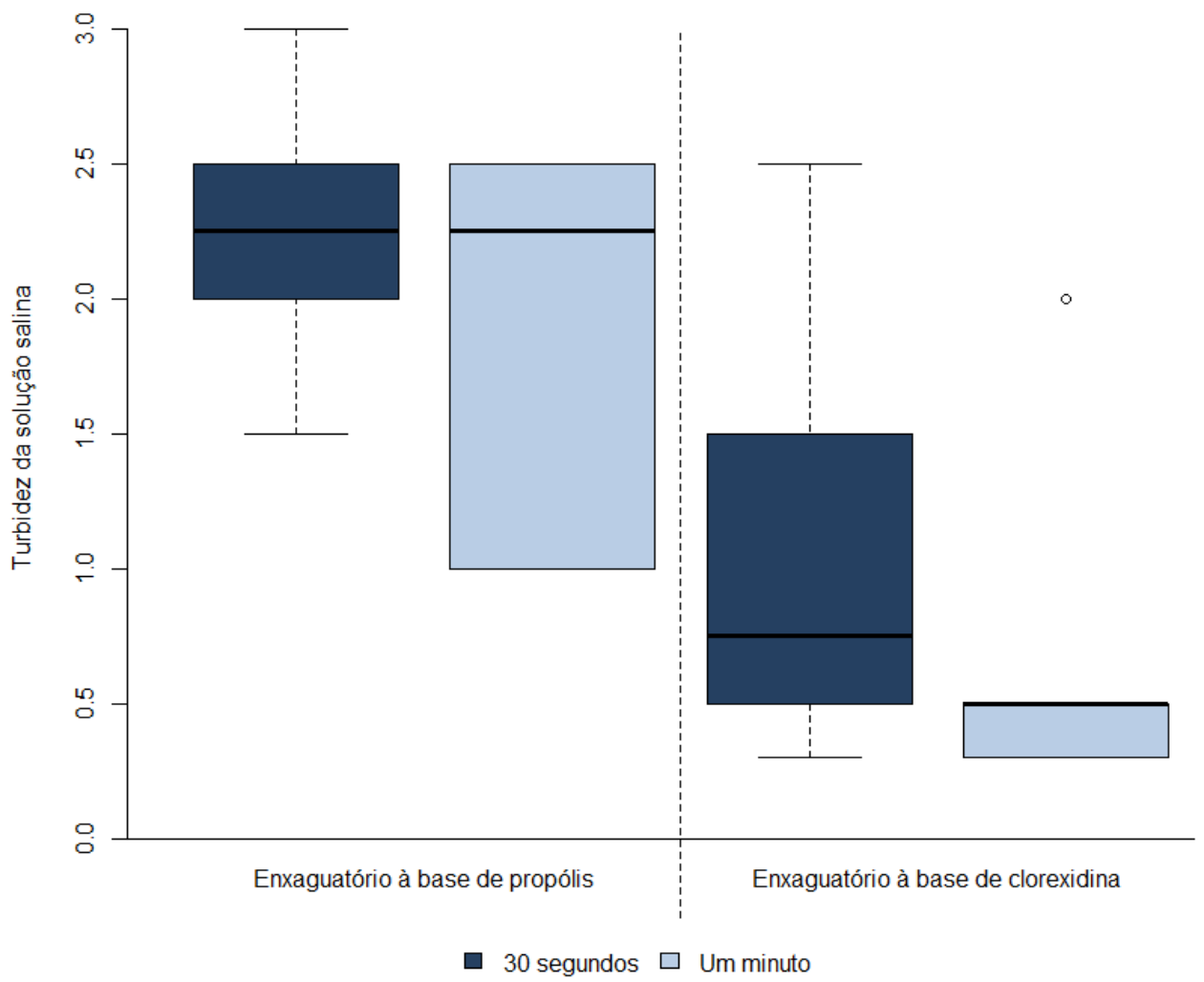

Fonte: Santos ID, et al., 2020. 
Analisou-se também a classificação da turbidez (Tabela 2), havendo associação significativa entre o grupo e a classificação da turbidez $(\mathrm{p}<0,05)$. Quando utilizado enxaguatório a base de própolis com 30 segundos de bochecho todos os pacientes tiveram turbidez acima de 1,00 na escala de Mc Farland. Quando utilizado com um minuto de bochecho, 30\% dos pacientes tiveram turbidez entre 0,50 e 1,00 na escala e 70,0\% tiveram resultado acima de 1,00 na escala. Para o enxaguatório à base de clorexidina por 30 segundos $30 \%$ apresentaram turbidez até 0,50 na escala, e 60,0\% apresentaram turbidez até 1,00 na escala. Já para o bochecho de um minuto, 90,0\% apresentaram turbidez de até 0,50.

Tabela 2 - Frequência (\%) da turbidez da solução salina, após aproximadamente 12 horas de cultura, classificação pela escala de Mc Farland (escala nefelométrica), em função do enxaguatório e tempo de bochecho.

\begin{tabular}{cc|cccc}
\hline \multirow{2}{*}{ Enxaguatórios } & \multirow{2}{*}{ Tempo } & \multicolumn{4}{|c}{ Turbidez } \\
\cline { 3 - 6 } & & $<=0,50$ & $0,50-1,00$ & $1,00-2,00$ & $2,00-3,00$ \\
\hline \multirow{2}{*}{ Própolis } & $30 \mathrm{~s}$ & $0(0,0 \%)$ & $0(0,0 \%)$ & $5(50,0 \%)$ & $5(50,0 \%)$ \\
\multirow{2}{*}{ Clorexidina } & $1 \mathrm{~min}$ & $0(0,0 \%)$ & $3(30,0 \%)$ & $2(20,0 \%)$ & $5(50,0 \%)$ \\
& $30 \mathrm{~s}$ & $3(30,0 \%)$ & $3(30,0 \%)$ & $3(30,0 \%)$ & $1(10,0 \%)$ \\
\hline
\end{tabular}

\section{Legenda: $p<0,05$}

Fonte: Santos ID, et al., 2020.

Em relação ao teste realizado em placas de cultura para verificação do crescimento microbiano pósenxague, com os diferentes colutórios através da contagem de Unidades Formadoras de Colônias, notamos que não houve uma diferença significativa em relação aos tempos de exposição de cada colutórios, considerando uma comparação intragrupo. Por outro lado, ao compararmos o crescimento entre os grupos que utilizaram clorexidina e própolis, foi possível notar um crescimento significativamente menor nas placas que foram semeadas com suspensões bacterianas colhidas de voluntários que realizaram o bochecho com clorexidina por 1 minuto. Reforçando nossos achados anteriores (Gráfico 1) sobre a necessidade de se manter este tempo de bochecho.

Na Tabela 3 pode-se notar claramente, uma interferência do fator tempo sobre os resultados, pois ao compararmos o crescimento microbiano verificado para ambos os colutórios no tempo de 30 segundos, não há diferença significativa, entretanto quando a solução de clorexidina age por um minuto uma tendência à inibição do crescimento microbiano se mostra significativa $(p>0,05)$.

Tabela 3 - Mediana (valor mínimo e máximo) dos escores de crescimento bacteriano - UFC, em função do enxaguatório e tempo de bochecho.

\begin{tabular}{c|ccc}
\hline \multirow{2}{*}{ Enxaguatórios } & \multicolumn{2}{|c}{ Tempo de bochecho } & p-valor \\
\cline { 2 - 3 } & 30 segundos & Um minuto & \\
À base de própolis & $3,00(1,00-4,00) \mathrm{a}$ & $4,00(3,00-4,00) \mathrm{a}$ & 0,1306 \\
À base de clorexidina & $1,50(0,00-4,00) \mathrm{a}$ & $1,50(0,00-4,00) \mathrm{b}$ & 0,9097 \\
p-valor & 0,0696 & 0,0012 & \\
\hline
\end{tabular}

Legenda: Letras diferentes comparando na vertical indicam diferença significativa ( $\leq \leq 0,05)$. 0: ausência de crescimento bacteriano; 1: pouco crescimento bacteriano; 2: médio/pouco crescimento bacteriano; 3 : médio/muito crescimento bacteriano e 4: muito crescimento bacteriano

Fonte: Santos ID, et al., 2020.

Quanto à percepção de sabor não houve associação significativa com o grupo (p>0,05). A maioria considerou os sabores moderado ou ótimo/ausente para os dois enxaguatórios (Tabela 4).

Tabela 4 - Frequência (\%) do escore de percepção de sabor, em função do enxaguatório e tempo de bochecho.

\begin{tabular}{cc|cccc}
\hline \multirow{2}{*}{ Enxaguatórios } & \multirow{2}{*}{ Tempo } & \multicolumn{3}{c}{ Sabor } \\
\cline { 3 - 5 } & & Ruim & Moderado & Ótimo/ausente & Não sei opinar \\
\hline \multirow{2}{*}{ Própolis } & $30 \mathrm{~s}$ & $2(20,0 \%)$ & $5(50,0 \%)$ & $3(30,0 \%)$ & $0(0,0 \%)$ \\
& $1 \mathrm{~min}$ & $\left.1(10,0 \%)^{\prime \prime}\right)$ & $6(60,0 \%)$ & $3(30,0 \%)$ & $0(0,0 \%)$ \\
\multirow{2}{*}{ Clorexidina } & $30 \mathrm{~s}$ & $0(0,0 \%)$ & $5(50,0 \%)$ & $4(40,0 \%)$ & $1(10,0 \%)$ \\
& $1 \mathrm{~min}$ & $0(0,0 \%)$ & $6(60,0 \%)$ & $4(40,0 \%)$ & $0(0,0 \%)$ \\
\hline
\end{tabular}

Legenda: valor de $p=0,8561$

Fonte: Santos ID, et al., 2020. 


\section{DISCUSSÃO}

Os microrganismos colonizadores da cavidade bucal podem causar uma série de doenças infecciosas bucais Estudos associam esta microbiota a infecções sistêmicas, podendo ter como porta de entrada, alguns procedimentos odontológicos, sendo, portanto importante a utilização de enxaguatórios bucais como antissépticos durante procedimentos odontológicos mais invasivos (PALONE MRT, et al., 2013). Um dos problemas dos medicamentos que promovem antibioticoterapia é a resistência dos microrganismos a eles. Sendo assim, há uma necessidade de estudar novos compostos (KARPINSKI TM e SZKARADKIEIWICZ AK, 2015).

A própolis ganhou atenção no campo odontológico devido às suas propriedades antimicrobiana, antifúngica, antiviral, anti-inflamatória, dentre outras. A sua atividade biológica está relacionada com seus compostos, principalmente aos flavonóides, ácido cafeico-fenetilico e ao ácido hidroxicinâmico (KHURSHID Z, et al., 2017; AKCA AE, et al., 2016; ERCAN N, et al., 2015).

De acordo com Khurshid Z, et al. (2017) e Vagish KLS (2014) há uma variabilidade química na composição da própolis. Isso ocorre devido às diferentes origens das plantas, bem como as regiões e estação do ano onde são cultivadas, flora local, e espécie de abelhas. Considerando esses fatores, acredita-se que a composição química da própolis interfira diretamente nas propriedades do composto, e, consequentemente, na sua eficácia representando mais uma variável a ser investigada em estudos futuros.

Estudo recente mostrou que a própolis brasileira apresenta efeitos antimicrobianos significativos contra a Streptococcus mutans da cavidade oral, sendo assim, pode ser usada como uma terapia natural alternativa contra uma condição infecciosa da cavidade oral (KHURSHID Z, et al., 2017). Entretanto, nosso estudo mostrou que o composto em questão não apresentou redução significativa da microbiota bucal ao serem analisados o nível de turbidez e o crescimento bacteriano nas placas dentro do tempo de bochecho proposto e na concentração utilizada da solução de própolis em comparação ao padrão ouro, a solução de clorexidina.

A clorexidina é o agente antimicrobiano mais amplamente pesquisado na área odontológica. Ela é comercializada na forma de dentifrícios, géis, vernizes e soluções para bochechos, sendo o último, em concentrações a $0,12 \%$, considerada como padrão ouro para controle dos microrganismos (JOHNSON NR, et al., 2015; LEE DW, et al., 2016).

Estudos mostram que o bochecho com clorexidina $0,12 \%$ durante 1 minuto é o mais indicado para redução das bactérias (SANTOS GO, et al., 2017; JOHNSON NR, et al., 2015). Entretanto, nosso estudo evidenciou que não houve diferença significativa na diminuição dos microrganismos quando realizados bochechos durante 30 segundos e 1 minuto ao observarmos o crescimento das UFC nas Placas de Petri. Entretanto, a análise realizada a partir da turbidez corrobora com a literatura ao verificarmos uma tendência à redução da população microbiana pela solução de clorexidina.

Esta ação antimicrobiana pode ser explicada pelo fato dela ser um antimicrobiano catiônico, que se une à célula microbiana mediante a ligação de uma região hidrofóbica e sua carga positiva forte, desestruturando a membrana citoplasmática da bactéria, fazendo com que esta perca fluidez, que resulta em sua morte (KARPINSKI TM e SZKARADKIEIWICZ AK, 2015; JOHNSON NR, et al., 2015; LEE DW, et al., 2016; DENNY J e MUNRO CL, 2017).

Com isso, a clorexidina apresenta maior eficácia contra as bactérias Gram positivas e menores contra as Gram negativas, uma vez que os microrganismos Gram positivos são mais vulneráveis a compostos catiônicos, devido ao fato de apresentar uma carga negativa, além de agir contra fungos e vírus (KIM HS, et al., 2013; KARPINSKI TM e SZKARADKIEIWICZ AK, 2015; JOHNSON NR, et al., 2015; LEE DW, et al., 2016; SANTOS GO, et al., 2017; BARATAKKE SU, et al., 2017;DENNY J e MUNRO CL, 2017).

Considerando que o uso prolongado do enxaguatório de clorexidina não é recomendado pela maioria dos profissionais, já que o mesmo apresenta efeitos colaterais, como coloração marrom extrínseca dos dentes e língua, alteração do paladar, ardência, descamação e dor da mucosa oral (VAN STRYDONCK DAC, et al., 2012; BARATAKKE SU, et al., 2017; KARPINSKI TM e SZKARADKIEIWICZ AK, 2015). 
O tempo de exposição ao colutório deve ser o menor possível e, apesar de não haver uma diferença significativa quanto à percepção de sabor tanto da clorexidina como da própolis nos tempos avaliados, é relevante destacar que o efeito inibitório do crescimento microbiano se mostrou seguro para o tempo de 1 minuto com a solução de clorexidina, significando que apesar de ser importante o uso deste colutório por menor tempo possível, o tempo mínimo de bochecho de um minuto deve ser respeitado para se alcançar melhor nível de antissepsia.

\section{CONCLUSÃO}

O presente estudo foi capaz de demonstrar que o colutório à base de clorexidina persiste como a melhor escolha, uma vez que ofereceu maior segurança ao inibir o crescimento microbiano de forma significativa. Apesar da percepção do sabor entre os colutórios testados não ter sido significativamente diferente, 0 colutório à base de própolis não apresentou a mesma atividade antisséptica no tempo e concentração testados não devendo ser utilizado como substituto nos pré e pós-operatórios. Sugerimos então que novos estudos acerca do uso da solução de própolis sejam delineados considerando diferentes concentrações, e/ou tempo de bochecho, para ampliar o espectro de colutórios, atendendo aos indivíduos com sensibilidade à clorexidina.

\section{AGRADECIMENTOS}

Somos gratas aos voluntários que participaram deste estudo e à Faculdade de Ciências Médicas e da Saúde de Juiz de Fora - SUPREMA/JF pela bolsa de estudos para o Projeto de Iniciação Científica e pelo fornecimento de infraestrutura técnica e laboratorial. Agradecimento especial ao Técnico de Laboratório da Instituição, Ronaldo Mota.

\section{REFERÊNCIAS}

1. AIREN B, et al. Antibacterial effect of propolis derived from tribal region on Streptococcus mutans and Lactobacillus acidophilus: An in vitro study. Journal of the Indian Society of Pedodontics and Preventive Dentistry. 2018;36:48-52.

2. AKCA AE, et al. The comparative evaluation of the antimicrobial effect of propolis with chlorhexidine against oral pathogens: an in vitro study. BioMed Research International 2016; 2016:3627463.

3. ARAÚJO DB, et al. Saúde bucal: a importância dos enxaguatórios com antissépticos. Revista de Ciências Médicas e Biológicas. 2015; 14:1-6.

4. ARTEAGOITIA A, et al. Does Chlorhexidine reduce bactermia following tooth extraction? A systematic review and meta-analysis. PLoS One. 2018; 13(4): e0195592.

5. BARATAKKE SU, et al. Efficacy of triphala extract and chlorhexidine mouth rinse against plaque accumulation and gingival inflammation among female undergraduates: A randomized controlled trial. Indian journal of dental research: official publication of Indian Society for Dental Research. 2017;28(1):49-54.

6. BOHNEBERGER G, et al., Fitoterápicos na odontologia, quando podemos utilizá-los? Brazilian Journal of health Review. 2019; 2(4): 3504-17.

7. CHEN WP, et al. Composition Analysis and Feature Selection of the Oral Microbiota Associated with Periodontal Disease. Biomed Research International. 2018; 2018:3130607.

8. DENNY J, MUNRO CL. Chlorhexidine Bathing Effects on Health-Care-Associated Infections. Biological Research for Nursing. 2017;19 (2):123-36.

9. ERCAN N, et al. The comparative effect of propolis in two different vehicles; mouthwash and chewing-gum on plaque accumulation and gingival inflammation. European journal of dentistry. 2015;9(2):272-76.

10. JOHNSONNR, et al. Bacterial comparison of preoperative rinsing and swabbing for oral surgery using $0.2 \%$ chlorhexidine. Journal of investigative and clinical dentistry. 2015;6(3):193-6.

11. KARPINSKI TM, SZKARADKIEIWICZ AK. Chlorhexidine - pharmaco-biological activity and application. European review for medical and pharmacological sciences. 2015; 19(7):1321-6.

12. KHURSHID Z., et al. Propolis: A natural biomaterial for dental and oral helthcare.Journal of dental research, dental clinics, dental prospects.2017; 11(4): 265-74.

13. KIM HS, et al. Antimicrobial effect of alexidine and chlorhexidine against Enterococcus faecalis infection. International journal of oral science. 2013;5(1):26-31.

14. LEE DW, et al. The antibacterial activity of chlorhexidine digluconate against Streptococcus mutans biofilms follows sigmoidal patterns. European journal of oral sciences. 2016;124(5):440-46.

15. MANAGUTTI A, et al. Evaluation of Post-surgical Bacteremia with Use of Povidone-lodine and Chlorhexidine During Mandibular Third Molar Surgery. Journal of maxillofacial and oral surgery. 2017; 16(4):485-90.

16. MORAWIEC T, et al. The Assessment of Oral Microflora Exposed to $3 \%$ Ethanolic Extract of Brazilian Green Propolis Preparation Used for Hygiene Maintenance following Minor Oral Surgeries. BioMed research international. 2015; 2015:869575. 
17. NCCLS - The National Committee for Clinical Laboratory Standards (NCCLS). Metodologia dos testes de sensibilidade a agentes antimicrobianos por diluiçao para bactéria de crescimento aeróbico: norma aprovada-6a ed. M7-A6. 2011; 23:1-81.

18. OPLUSTIL CP, et al. Procedimentos básicos em microbiologia clínica. 3nd ed. São Paulo: Sarvier, $2010 ; 120$ p.

19. PALONE MRT, et al. A importância do controle da microbiota bucal e o uso de biomaterial em cirurgias de enxerto alveolar secundário nos pacientes com fissura labiopalatina. Investigação. 2013;13(2):19-23.

20. SANTOS GO, et al. Chlorhexidine with or without alcohol against biofilm formation: efficacy, adverse events and taste preference. Brazilian oral research. 2017; 31: e32.

21. TORETI VC, et al. Recent progress of propolis for its biological and chemical compositions and its botanical origin. Evidence-based complementary and alternative medicine. 2013; 2013:697390.

22. VAGISH KLS. Propolis in dentistry and oral cancer management. North American journal of medical sciences.2014; 6(6):250-9.

23. VAN STRYDONCK DAC, et al. Effect of a chlorhexidine mouthrinse on plaque, gingival inflammation and staining in gingivitis patients: a systematic review. Journal of clinical periodontology.2012; 39(11):1042-55. 